\title{
Atomic force microscopy analysis of the surface alterations of enamel, dentin, composite and ceramic materials exposed to low oral pH in GERD
}

\author{
ALINA MONICA PICOȘ ${ }^{1 *}$, IOAN PETEAN ${ }^{2 *}$, ANDREI PICOȘ ${ }^{3 *}$, ALEXANDRA DĂDÂRLAT-POP $^{4}$, \\ ANDREEA-LIANA RĂCHIȘAN ${ }^{5}$, ANAMARIA MAGDALENA TOMȘA ${ }^{5}$, NARCISA MĂDĂLINA PETRĂCHESCU ${ }^{6}$, \\ CRISTIAN PETRI ${ }^{7}$, MÂNDRA EUGENIA BADEA ${ }^{1}$ and IRINA DORA MĂGUREAN ${ }^{8}$
}

\footnotetext{
${ }^{1}$ Department of Dental Prosthetics, 'Iuliu Haţieganu' University of Medicine and Pharmacy, 400000 Cluj-Napoca;

${ }^{2}$ Faculty of Chemistry and Chemical Engineering, 'Babes Bolyai' University, 400028 Cluj-Napoca;

${ }^{3}$ Department of Prevention in Dental Medicine, 'Iuliu Haţieganu' University of Medicine and Pharmacy;

${ }^{4}$ Department of Cardiology 'Nicolae Stancioiu' Heart Institute, 'Iuliu Haţieganu' University of Medicine and Pharmacy;

${ }^{5}$ Department of Pediatrics II, ${ }^{6}$ Second Department of Internal Medicine,

'Iuliu Haţieganu' University of Medicine and Pharmacy, 400000 Cluj-Napoca; ${ }^{7}$ ArtChrys Dental Laboratory, 400664 Cluj-Napoca; ${ }^{8}$ Department Photo-Video, University of Arts and Design, 400148 Cluj-Napoca, Romania
}

Received February 19, 2021; Accepted March 23, 2021

DOI: $10.3892 /$ etm.2021.10105

\begin{abstract}
Dental erosion is a significant topic in medical literature, both for gastroenterology and dental medicine. Dental structure loss has a psychosocial and functional significance. The pathogenesis of dental erosion in patients diagnosed with gastroesophageal reflux disease (GERD) characterized by the presence of an acidic oral environment after reflux episodes, is not well understood. The present study was designed to observe the effect of low oral $\mathrm{pH}$ in time on natural surfaces including enamel and dentine, but also on materials used in treating these dental destructions such as composites and ceramics. The acidic oral environment was estimated in relation to salivary $\mathrm{pH}$. In the dental laboratory, $5-\mathrm{mm}^{2}$ and 1-mm composite pieces of thick enamel, dentine, Emax Ceramic and Nexco Ivoclar were cut in order to be analyzed using atomic force microscopy (AFM) and to observe the surface alterations. Gastric acid was collected and mixed with saliva until a pH value of 6.0 was obtained, in which the pieces were immersed for 24, 120, $240 \mathrm{~h}$. Roughness of each surface was calculated at a microstructure and nanostructure level. The results showed significant alterations in enamel and dentine
\end{abstract}

Correspondence to: Dr Andrei Picoş, Department of Prevention in Dental Medicine, 'Iuliu Haţieganu' University of Medicine and Pharmacy, 70A Bucuresti Street, 400000 Cluj-Napoca, Romania E-mail: andrei.picos@umfcluj.ro

*Contributed equally

Key words: atomic force microscopy, e.max ceramic, composite, dentine, enamel, gastroesophageal reflux disease, dental erosion exposed to a lower $\mathrm{pH}$ level beginning even at a short immersion time, in comparison with composites and ceramics which had no alterations. In conclusion, multidisciplinary attention should be given to detect and manage acidity of the oral cavity caused by GERD, in order to prevent dental erosion.

\section{Introduction}

Dental erosion (DE) represents a subject of interest and concern for dentists because of its increasing prevalence in the last few years (1). Beside the medical significance, the quality of the teeth has a tremendous aesthetic effect involving psychosocial and artistic significance. DE leads to both alterations in physiognomy and to health issues (2). A common cause of DE includes an increase in oral cavity acidity by gastroesophageal reflux disease (GERD) (3). GERD is diagnosed as a result of heartburn and is assessed by intra-esophageal $\mathrm{pH}$-impedance monitoring; guidelines mention extraesophageal complications, including DE $(4,5)$. Unlike GERD, there are no diagnostic, prevention and treatment guidelines for $\mathrm{DE}$ at present. The mechanisms of action of gastric juice in the oral cavity are known; salivary $\mathrm{pH}$ decreases with individual variations according to the buffer capacity and the chemical composition (calcium and phosphorus) of the saliva (6-14).

$\mathrm{DE}$ is the result of the repeated or continuous exposure of hard dental tissues to acidic $\mathrm{pH}$ condition and it includes three consecutive stages: Loss of the protective matrix on the enamel, its demineralization at a salivary $\mathrm{pH}$ below 5.5 and alteration of the dentin structure, with opening of the dentinal tubules (15-20). The duration and frequency of reflux episodes is relative. Many studies report different values, from $1 \mathrm{~min}$ to $2 \mathrm{~h}$, one to 15 episodes within $24 \mathrm{~h}$ (21-27).

GERD may be asymptomatic but can still induce DE (28). Therefore, it is important to complete a dental exam for DE 
with a gastroenterological examination that would confirm a diagnosis of GERD. Of the GERD patients who present with DE, 31-56\% have distal GE reflux. Patients with more than 2 reflux episodes per week were found to have a longer distal esophageal exposure time to $\mathrm{pH}$ values below 4.0 and 5.5 according to a previous study (28).

Atomic force microscopy (AFM) enables surface scanning and 3D presentation of its aspect. Such details can provide important information on the mechanism of erosion. The images may be explored and analyzed by the dentist in a new and interactive manner.

Atomic force microscopy differs from classic microscopy by enabling a $3 \mathrm{D}$ view of the surface studied. The high cost of the equipment makes it available in only a few medical centers; therefore, the number of studies is also small (29-32).

Given the alterations induced by gastric acid on dental surfaces, we analyzed the physical modifications and their evolution by a multidisciplinary team including physicians and physicists. The aim of this study was to assess, by AFM, the roughness value of enamel, dentine, and the materials used in minimal invasive treatments for DE such as composites and ceramics, exposed to a low $\mathrm{pH}$ level in the oral cavity as a consequence of gastric reflux.

\section{Materials and methods}

An in vitro experiment on enamel, dentin, dental composite Nexco and Emax ceramic was designed. The present study included dental surfaces submitted to acid erosion in the mouth, namely enamel and dentin. The behavior of ceramic and composite materials used in the prosthetic restorative treatments of erosion was also assessed. Preparations of the samples were conducted in the 'ArtChrys Dental Lab' in Cluj-Napoca, Romania by a dental technician and a dentist. Four dentin and 4 enamel surfaces were prepared in the shape of a parallelepiped, one side 5 and $1 \mathrm{~mm}$ thickness, polished with a disk, from 8 central extracted incisors that presented no signs of erosion. The 4 ceramic surfaces Emax IPS (Ivoclar), one of the most frequently used ceramic facets, were made to be square shaped, $5 \mathrm{~mm}$ in size, $1 \mathrm{~mm}$ in thickness. The composite surfaces, Nexco (Ivoclar), used in direct dental reconstruction were the same size, photopolymerized for $40 \mathrm{sec}$ and polished with abrasive disks and special rubbers. All the samples were maintained in the saliva harvested after meals from patients without GERD, medium buffer capacity, in order to prevent dehydration and realize a protective layer similar to the conditions in the mouth.

In all, there were 16 surfaces divided into 4 groups of 4 samples each: Enamel, dentin, Emax IPS ceramic and Nexco (Ivoclar) composite. For each group, one surface, not exposed to acid, was studied by AFM and served as a normal control, attributed to control patients without GERD.

From one patient diagnosed with GERD, as confirmed by endoscopy, and admitted to the 2nd Department of Internal Medicine, 'Iuliu Haţieganu' University of Medicine and Pharmacy in Cluj Napoca, $120 \mathrm{ml}$ gastric juice was collected by endoscopy. Each sample was immersed in $10 \mathrm{ml}$ gastric juice mixed with saliva, $\mathrm{pH}$ of 6.0 , as tested by GC Saliva Check (33).
All the surfaces, following immersion, were examined by AFM at 24, 120 and $240 \mathrm{~h}$. These intervals were chosen as being equivalent to 1,5 and 10 years of exposure of dental tissues and prosthetic materials to an oral acid $\mathrm{pH}$ for $15 \mathrm{~min}$ - the time of a GE reflux (salivary buffer restores the $\mathrm{pH}$ to normal within about 15 min after a sudden drop to acid). We chose a frequency of 2 gastroesophageal episodes per week, a threshold value most used in studies (28).

Preparation of the samples for AFM analysis was conducted after their extraction from the immersion solution. This preparation included intense washing with double distilled water and natural drying on paper. They were then mounted onto a specific support, with the studied surface upward.

The effect of the acid on the teeth was assessed and approved by a professional visual artist working with image processing.

For each sample, we examined two surfaces by AFM to confirm the results. Examination was conducted in tapping mode, in environmental conditions at $20^{\circ} \mathrm{C}$, using microscope JSPM 4210 (Jeol Co. Japan). Minikit used was NSC15 (MikroMasch Co.) with a silicone tip and $300 \mathrm{kHz}$ resonance frequency. Topographic images were obtained at approximately $\mathrm{x} 1 \mathrm{~Hz}$ on surfaces from $5 \times 5$ to $1 \mathrm{x} 1 \mu \mathrm{m}$. All images were processed using WinSPM 2.0 software (JEOL), which provided data on the sample surface, diameter of morphological changes and roughness values.

The patient gave informed consent. The study was conducted according to the Helsinki Declaration on Human and Animal Studies.

\section{Results}

Gastric reflux has a complex acid profile as it includes not only acids from ingested food, but also gastric juice containing diluted hydrochloric acid among other components with a role in digestion. Long-term exposure of teeth to GE reflux leads to severe alterations in the morphology and structure of enamel and dentin. We recorded, using AFM, the evolution in time of enamel and dentin after immersion in acidic solution, using as controls healthy enamel and dentin samples. The roughness values in this study are the means of 3 measurements per each sample.

Enamel. The AFM examination of the state of the enamel evidenced 2 structure areas: The microstructural area, best observed at a scan area of $5 \times 5 \mu \mathrm{m}$, and the nanostructural area, at an area of $1 \mathrm{x} 1 \mu \mathrm{m}$.

Microstructure of the healthy enamel. Microstructure of the healthy enamel presented with a smooth and even surface of crystallites and hydroxyapatite (HAP) well bonded together. We note some small dips on this surface (the darker spots), which are normal for healthy enamel. In these conditions, the microstructural roughness was $\mathrm{R}_{\mathrm{q}}=9.69 \mathrm{~nm}$ (Fig. 1A).

Nanostructure of the healthy enamel. The nanostructure of the healthy enamel is presented in Fig. 1E. It shows a compact crystallite and HAP structure, well bonded, $40 \mathrm{~nm}$ in diameter. The surface is very smooth, roughness $\mathrm{Rq}_{\mathrm{q}}=2.14 \mathrm{~nm}$. However, some HAP crystallites have higher positions in the surface topography, while others are lower. This led to local 
A

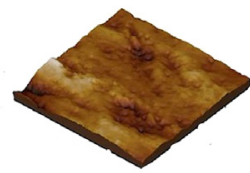

B

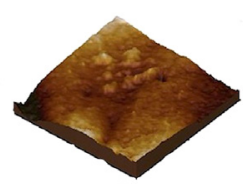

C

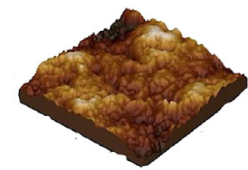

D

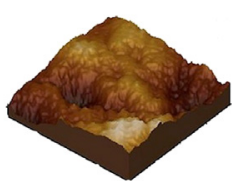

E
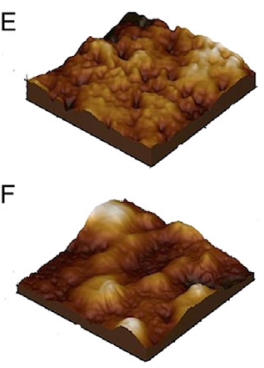

G

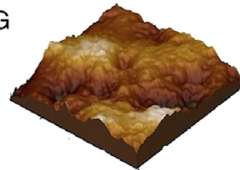

$\mathrm{H}$

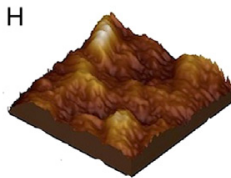

Figure 1. 3D AFM images of enamel samples affected by GERD. Evolution of the microstructure $(5 \times 5 \mu \mathrm{m})$ of (A) healthy enamel, and after (B) 1 year (C) 5 years, and (D) 10 years of aggression. Evolution of the nanostructure $(1 \mathrm{x} 1 \mu \mathrm{m})$ of (E) healthy enamel, and after $(\mathrm{F}) 1$ year, $(\mathrm{G}) 5$ years, and (H) 10 years of aggression. GERD, gastroesophageal reflux disease; 3D, three dimensional; AFM, atomic force microscopy.

depressions (darker spots) of 10-50 $\mathrm{nm}$ in diameter. Still, these represent a natural characteristic of healthy enamel, becoming vulnerable at a lengthy exposure to acid-erosive conditions.

Evolution of the microstructure. Evolution of the microstructure of the enamel surface in relation to time of exposure is presented in Fig. 1B-D. Evolution of the microstructure of the enamel is presented after 1 year of aggression (Fig. 1B), after 5 years (Fig. 1C), and after 10 years (Fig. 1D). After 1 year of acid erosion the microstructure of the enamel surface was barely changed, with only some well-defined uneven areas being visible at the top of the image (Fig. 1B). This caused a slight increase in the $\mathrm{Rq}$ value to $9.75 \mathrm{~nm}$. We noted that the small natural dips became slightly more visible. After 5 years of acid erosion, the microstructure morphology was drastically altered; the small dips progressed to a diameter of $>200 \mathrm{~nm}$ and with considerable depths (Fig. 1C). These were integrated into the surface topography by depth, while the local irregularities observed at 1 year extended to the whole surface after 5 years, causing some local pikes (lighter spots almost white). This affected the roughness significantly, reaching $\mathrm{Rq}=23.7 \mathrm{~nm}$. Ten years of acid-erosive aggression was found to lead to a totally destroyed enamel surface, resembling that noted at 5 years but very uneven, with depressions of 100-200 $\mu \mathrm{m}$ in diameter and variable depths reaching even $100 \mathrm{~nm}$. This caused heavily roughness, with $\mathrm{Rq}=42.7 \mathrm{~nm}$.

Evolution of the nanostructure. The evolution of the enamel surface nanostructure according to the GE reflux aggression is presented in Fig. 1F-H. After one year of acid aggression by GE reflux the enamel nanostructure underwent significant alterations (Fig. 1F). Entire nanostructural areas became demineralized, namely the HAP crystallites were dissolved from the superficial layer, forming depressed zones, while the remaining ones formed higher islets. The diameter of the HAP crystallites on the aggressed surface was markedly increased to $60 \mathrm{~nm}$. This led to more roughness, $\mathrm{R}_{\mathrm{q}}=4.21 \mathrm{~nm}$. After 5 years (Fig. 1G) the nanostructure progressed to deeper areas and erosion of the margins of resisting islets, forming a rugged surface of $\mathrm{R}_{\mathrm{q}}=11.0 \mathrm{~nm}$. The HAP crystallites diameter was $80 \mathrm{~nm}$, almost double of the initial phase, which indicates evidence of erosive-acid decay. After 10 years (Fig. 1H) the nanostructure was deeply affected, evidenced by the deep areas associated with the flattening of HAP formations, $\mathrm{R}_{\mathrm{q}}=16.0 \mathrm{~nm}$.

Values of roughness. The 3D surface roughness of enamel alterations are presented in Fig. 1. The values of roughness that resulted at the microstructural and nanostructural levels are presented in Fig. 2. The complex aspect of the acid erosion on the dental enamel is evidenced. We noted that surface erosion started at a nanostructural level after 1-year exposure, with the microstructure being less affected. Beyond one year, alterations become more obvious. At 5 years, the nanostructural roughness reached the initial microstructural values and surpassing them after a period of 10 years (Fig. 2).

Summing up the findings, we may conclude that after 5 years and later, GE reflux has severe effects on the dental enamel, manifested by decay, which may reach the dentin in patients with thin enamel or dental surface injuries. Consequently, this led us to investigate how dentin reacts to acid aggression.

Dentin. Dentin is a bio-composite formed of HAP crystallites, about $40 \mathrm{~nm}$ in diameter, well bonded by an organic network of collagen fibers. It is more heterogeneous in structure than enamel and more susceptible to surface alterations. Data in the literature show that dentin demineralization under acid circumstances is caused by progressive depletion of HAP crystallites, while the collagen network remains in place. Acid mineral loss may leave dentin totally depleted of HAP, in which case only collagen fibers are seen (34).

Dentin, the matter of which teeth are made of, cannot be visualized by AFM; thus, the samples needing adequate sectioning and preparation. Dental samples in our study were sectioned from healthy teeth, so that the plane-parallel facets could be polished to be shiny for optical visualization.

Microstructure of the healthy dentin. Considering these aspects, microstructure of the healthy dentin is shown in Fig. 3A at a scan area of 5x5 $\mu \mathrm{m}$. It presents a smooth and compact surface with a topography characterized by densely mineralized HAP. Microstructural ruggedness of the healthy dentin was $\mathrm{R}_{\mathrm{q}}=30.7 \mathrm{~nm}$.

Nanostructure of the healthy dentin. The nanostructure of the healthy dentin may be well visualized at $1 \mathrm{x} 1 \mu \mathrm{m}$ scan. The surface texture included collagen fibers densely mineralized with HAP crystallites, $40 \mathrm{~nm}$ in diameter. The roughness was approximately $\mathrm{R}_{\mathrm{q}}=4.59 \mathrm{~nm}$ (Fig. 3E).

Evolution of the microstructure. After one year of GE reflux aggression, the dentin microstructure underwent significant changes (Fig. 3B). Numerous HAP crystallites were dislodged 


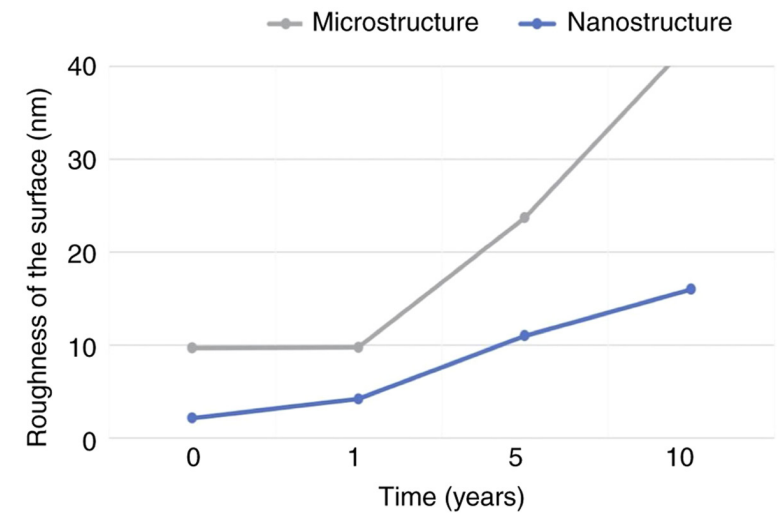

Figure 2. Variation in the roughness of the enamel surface in relation to the time of exposure to GERD. GERD, gastroesophageal reflux disease.
A

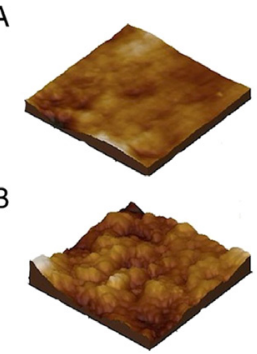

C

D

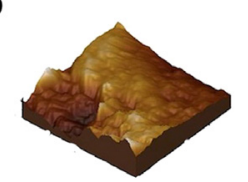



E

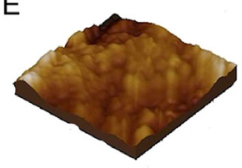

F

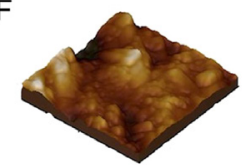

G

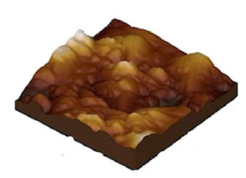

$\mathrm{H}$

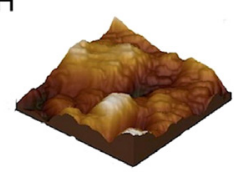

Figure 3. 3D AFM images of dentin samples affected by GERD. Evolution of the microstructure (5x5 $\mu \mathrm{m})$ of (A) healthy unexposed dentin, and exposed for (B) 1 year, (C) 5 years and (D) 10 years. Evolution of the nanostructure $(1 \mathrm{x} 1 \mu \mathrm{m})$ of (E) healthy unexposed dentin, and exposed for (F) 1 year, (G) 5 years and $(\mathrm{H}) 10$ years. GERD, gastroesophageal reflux disease; 3D, three dimensional; AFM, atomic force microscopy.

from the surface, which became uneven, with depressions of approximately 200-700 $\mathrm{nm}$. This doubled the roughness index to $\mathrm{Rq}=62.7$. After 5 years, the dentin microstructure was seriously damaged. Its surface was an alteration of well delimited pikes with grooves and dips in which collagen strings may be observed (Fig. 3C). Roughness reached a value $\mathrm{Rq}=137 \mathrm{~nm}$. The degree of erosion was even higher after 10 years of GE reflux aggression (Fig. 3D), with a roughness value $\mathrm{R}_{\mathrm{q}}=322 \mathrm{~nm}$.

Evolution of the nanostructure. At the nanostructure level, after 1-year exposure the dentin surface presented with partially demineralized collagen strings and dips formed by the elimination of surface HAP crystallites (Fig. 3F). There was also an effect of surface crystallite wear; diameter of approximately $80 \mathrm{~nm}$. Roughness at the nanostructural level reached $\mathrm{Rq}=22.9 \mathrm{~nm}$. Surface alteration and erosion became more marked after 5 years (Fig. 3G), leading to a roughness value

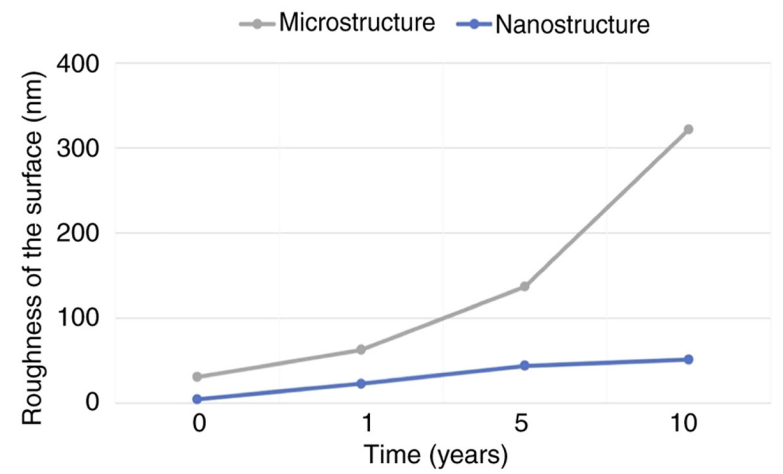

Figure 4. Variation in the dentin roughness in relation to the time of exposure to GERD. GERD, gastroesophageal reflux disease.

$\mathrm{Rq}=44.0 \mathrm{~nm}$. After 10 years of acid aggression on the dentin, the decay was advanced with an alteration of nanostructural and submicron pikes and dips, $\mathrm{Rq}=51.3 \mathrm{~nm}$ (Fig. $3 \mathrm{H}$ ).

The values of roughness in the dentin samples submitted to acid aggression by GE reflux can be seen in Fig. 4. It may be evidenced that as soon as dentin is exposed to acid attack, at a microstructural level roughness increases progressively to 10 times more than the initial value after 10 years. At a nanostructural level, it progresses rapidly, reaching the microstructural initial value after 5 years, and also after 10 years (Fig. 4 ).

Ceramic and composite materials. Ceramic and composite materials were also tested for gastric acid aggression. In their case, the optimal scanning area was $2.5 \times 2.5 \mu \mathrm{m}$. AFM images are presented in Fig. 5.

Ceramic material unexposed to gastric reflux. The ceramic material presented with a heterogeneous submicronic structure based on tabular polyhedric crystals, $150 \mathrm{~nm}$ wide and approximately $300 \mathrm{~nm}$ long, included into a very compact mass (Fig. 5A). Surface roughness was $\mathrm{R}_{\mathrm{q}}=20.0 \mathrm{~nm}$.

Ceramic material exposed to gastric reflux. Exposure to gastric reflux for 1 year (Fig. 5B), 5 years (Fig. 5C) and 10 years (Fig. 5D) did not alter ceramic microstructure, which preserved its shape and size. The roughness increased slowly, doubling its value only after 10 years of acid attack. Given the preserved shape and size, the mild increase in roughness may be explained by the relative flattening of the lower areas, while ceramic crystals preserved their initial value. The evolution of roughness may be observed in Fig. 6. Overall, we demonstrated good resistance of the ceramic material to erosion by GE reflux for 10 years.

Composite material unexposed to gastric reflux. The unexposed composite material presented a granular structure with an average diameter of $80 \mathrm{~nm}$, well compacted by the bonding matter (Fig. 5E). Its surface was quite smooth, with roughness of $24.1 \mathrm{~nm}$.

Composite material exposed to gastric reflux. We found that the morphology, dimensions, and roughness of the surface were preserved at 1 year (Fig. 5F), 5 years (Fig. 5G) 
Table I. Surface roughness of the analyzed material before and after exposure to acidic environment.

Surface roughness of material in $\mathrm{nm}$

\begin{tabular}{|c|c|c|c|c|c|c|}
\hline \multirow{2}{*}{$\begin{array}{l}\text { Acidic exposure } \\
\text { simulation in years }\end{array}$} & \multicolumn{2}{|c|}{ Enamel } & \multicolumn{2}{|c|}{ Dentine } & \multirow{2}{*}{$\begin{array}{c}\text { Ceramic } \\
\text { Microstructure }\end{array}$} & \multirow{2}{*}{$\begin{array}{c}\text { Composite } \\
\text { Microstructure }\end{array}$} \\
\hline & Microstructure & Nanostructure & Microstructure & Nanostructure & & \\
\hline 0 & 9.69 & 2.14 & 30.70 & 4.59 & 20.00 & 24.10 \\
\hline 1 & 9.75 & 4.21 & 62.70 & 22.90 & 27.30 & 22.30 \\
\hline 5 & 23.70 & 11.00 & 137.00 & 44.00 & 45.30 & 15.50 \\
\hline 10 & 42.70 & 16.00 & 322.00 & 51.30 & 58.80 & 20.00 \\
\hline
\end{tabular}

A

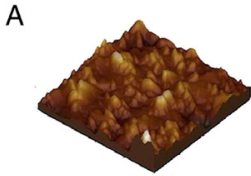

$\mathrm{B}$

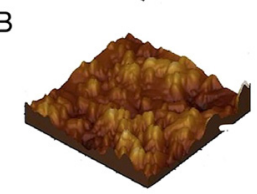

E

C


Figure 5. 3D AFM images of ceramic and composite samples affected by GERD. Ceramic samples: (A) unexposed ceramic samples, and exposed for (B) 1 year, (C) 5 years and (D) 10 years. Composite samples: (E) unexposed composite samples and exposed for $(\mathrm{F}) 1$ year, $(\mathrm{G}) 5$ years and $(\mathrm{H}) 10$ years. GERD, gastroesophageal reflux disease; 3D, three dimensional; AFM, atomic force microscopy.

and 10 years (Fig. 5H) of acid aggression by GE reflux. The evolution of roughness is also presented in Fig. 6.

There are numerous studies $(4,6,10)$ in the literature on the demineralization of dental enamel under the acid action from different components in food, mainly phosphoric and citric acids. A modern approach of enamel demineralization uses AFM to monitor the changes in surface morphology and size. The method allows a follow-up of these changes at high resolution (35).

The understanding of the etiopathogenetic mechanism of dental wear and awareness regarding prevention and early treatment by minimally invasive methods can help the patient maintain healthy hard dental structures and enjoy a good quality of life.

Summing up our findings at the microstructural and nanostructural levels, we may state that the decay of dentin surface is a process starting at the nanostructural level by progressive loss of surface HAP crystallites, which rapidly influences microstructure. We noted a weaker resistance of dentin to acid action and a more marked decay of its surface in comparison to enamel (Table I).

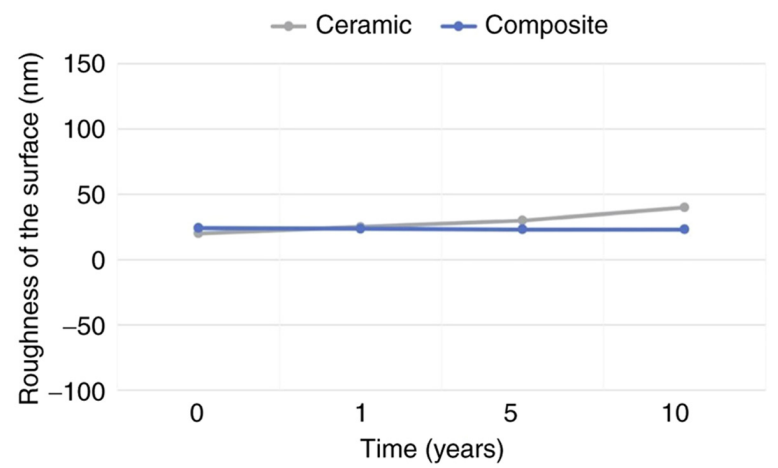

Figure 6. Variation in the surface roughness of ceramic and composite materials according to the time of exposure to GERD. GERD, gastroesophageal reflux disease.

Analyzing the AFM results on the ceramic and composite materials, we found that they maintain their morphology and size in time, which confirms good resistance (Table I). It is difficult to conclude which of the two materials, ceramic or composite is more indicated as the therapeutic choice, as both performed well under the given conditions. The morphologic-topographic factor cannot be decisive in choosing one or the other. The choice should be based on the requirements of the dental appliance. Only in this case would it matter that for the ceramic material a slow but progressive roughness was found in time, while the composite roughness was constant. It is known that surface roughness is important in the retention of oral bacterial plaque, involved in the onset of dental caries by local demineralization and action of cariogenic bacteria (Streptococcus mutans, Lactobacillus) and maintenance of local acid $\mathrm{pH}$. Prevention in dentistry may ensure the control of dental plaque by periodical professional cleaning and topic fluoridation (36-39).

\section{Discussion}

In the present study, the atomic force microscopy (AFM) analyses indicated that gastroesophageal reflux had a deleterious effect on the morphology and roughness of enamel and dentin surfaces. A prolonged exposure of 5-10 years caused important dento-maxillary functional alterations that severely affected the dental system.

The period of time of the contact between the erosive agent and the tooth is more important than the $\mathrm{pH}$ acidity (38). 


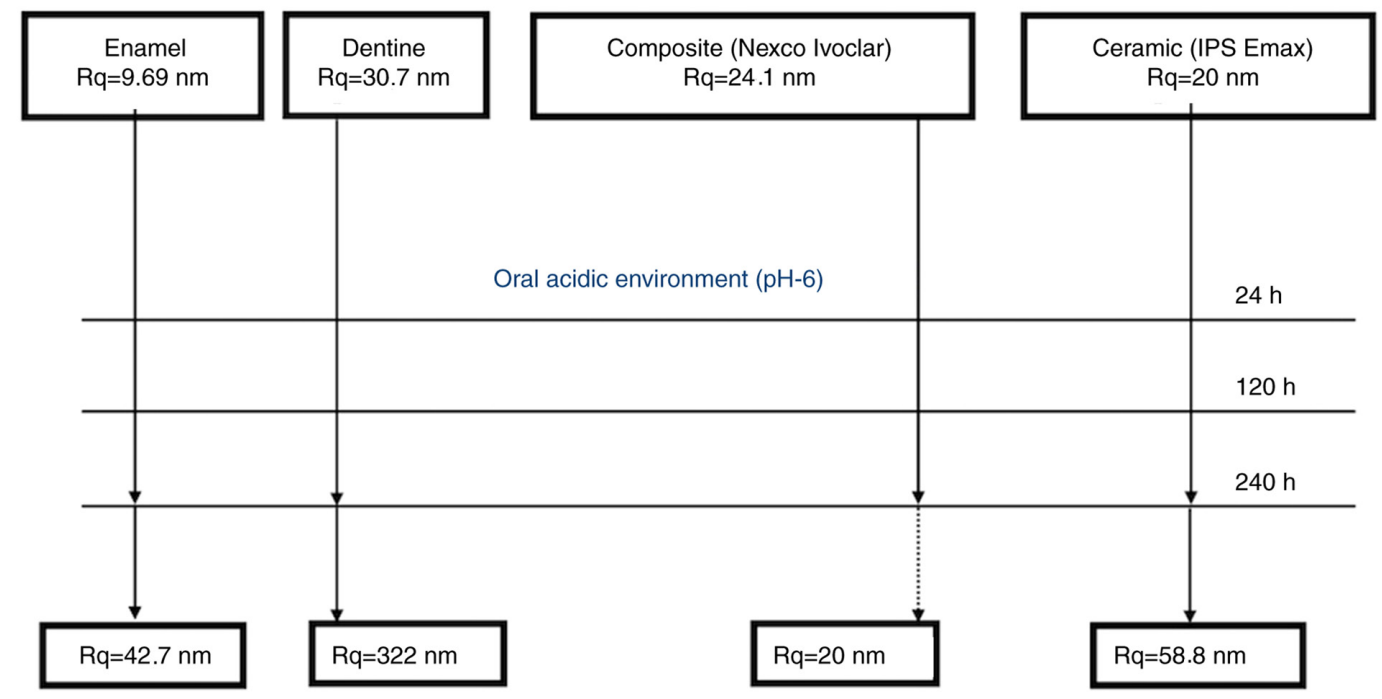

Figure 7. Enamel, dentine, composite and ceramic microstructure analysis with AFM of surface roughness after $240 \mathrm{~h}$ of immersion in $\mathrm{pH} 6.0$ liquid. AFM, atomic force microscopy.

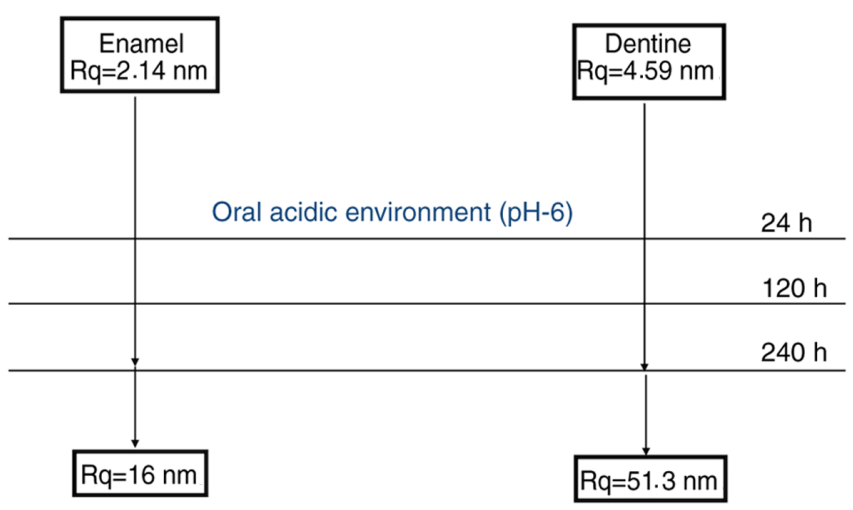

Figure 8. Enamel and dentine nanostructure analysis with AFM of surface roughness after $240 \mathrm{~h}$ of immersion in $\mathrm{pH} 6.0$ liquid. AFM, atomic force microscopy.

A profound and detailed knowledge of dental erosion mechanisms requires ample studies performed on a large number of samples over a long period of time of up to 30 years. Often $\mathrm{DE}$ is associated with other dental wear mechanisms, which favors rapid decay of dental structures and fostering difficulties of etiological diagnosis (25,40-43). Abrasion and attrition will dislodge more easily the eroded dental structures; this is obvious in many cases of bruxism or bad habits in patients with GERD, unhealthy diets, or heavy consumption of acidic foods or beverages $(44,45)$. This is how Lussi et al explains the appearance of cupules at the level of the cusps, which are typic for dental erosion and in which the acid is retain for long times because it is not washed away by saliva (39-41).

Composite materials present a porous structure that determines an increased adherence of the bacterial plaque, even if their surface is well polished. Ceramic materials being glazed do not present porosity, which minimizes the adherence of bacterial plaque $(46,47)$ (Figs. 7 and 8).

We consider that documenting the progressive erosion in time of dentin and enamel represent a novel study (Figs. 7 and 8). We also wanted to compare the resistance in time of ceramic materials and composites exposed to the same acid aggression, in order to obtain conclusive information on the changes undergoing at surfaces exposed to acid and thus orient the optimal materials to be used for treatment.

The ceramic and composite material investigated in the present study proved to have good resistance to the erosion caused by gastroesophageal reflux disease (GERD), with preserved form and dimensions, and even roughness after 10 years. The composite was found more stable regarding roughness than ceramic. However, we should keep in mind that there are many other mechanical forces of wear at work on composites as compared to ceramic masses.

The behavior of the prosthetic materials examined in our study indicates the choice of composites for crown restorations of eroded teeth. In a previous study on the behavior of cements in acid environment, we found that glass ionomers are less resistant to acid compared to resin cements, therefore contraindicated in patients with dental erosions (42).

In addition to the health issues consequent to dental erosion (DE), dental structure loss has important psychosocial and aesthetic consequences $(48,49)$. In order to study and establish an aesthetic dental treatment plan, extraoral and intraoral professional photography is needed. Photos obtained are used for aesthetic guidelines and can be coordinated with digital smile design, a special computer program or phone application that allows the doctor to create and the patient to previsualize the final result of the treatment, collaborating together. Indeed, beauty is also enhanced in association with a healthy oral cavity with a healthy smile. Minimal invasive treatment for dental erosions that use composites and ceramic veneers is considered a correct approach among experienced dentists. The art of creating a smile is motivating doctors to find advances in technology and to identify more aesthetic correlations between teeth and facial anatomy. Giving the power of creating dental morphology in the hands of the dentist, facial harmony is obtained, and together with functionality, long term results that satisfy patient needs are reached (50-52). Special attention to DE must be given by the gastroenterologist in collaboration with the dentist, as GERD is a disease with a genetic predisposition, and prevention is required (53). 


\section{Acknowledgements}

Not applicable.

\section{Funding}

Personal funding was used for the present study.

\section{Availability of data and materials}

Data are available at request and are stored in our personal database.

\section{Authors' contributions}

AMP realized the research conception, and was responsible for the design of the article and acquisition of materials. AMP also revised the work, examined the patients, edited the tables and figures, analyzed and interpreted the data. IP analyzed the dentin, enamel, composite and ceramics with the atomic force microscope. AP realized the conception of the article, handled the dentin, enamel, ceramic and composites immersion in gastric juice mixed with saliva, prepared the substance for the immersion, edited the tables and figures, analyzed and interpreted the data. ADP revised the article and edited the data and research study. ALR and AMT examined the patient and collected and tested $\mathrm{pH}$ level and buffer capacity of saliva. NMP performed the examination and diagnosis of GERD patients and collected the gastric juice. $\mathrm{CP}$ prepared the restorative materials, ceramics and composites in the dental laboratory. MEB supervised and revised the work, structure, steps, information and corrected the article. IDM documented the work and analyzed and edited the photographs. All authors read and approved the final manuscript.

\section{Ethics approval and consent to participate}

The study was conducted according to the Declaration of Helsinki on Human and Animal Studies. Written informed consent was obtained from the patient.

\section{Patient consent for publication}

Not applicable.

\section{Competing interests}

The authors declare that they have no competing interests.

\section{References}

1. Picos A, Badea ME and Dumitrascu DL: Dental erosion in gastro-esophageal reflux disease. A systematic review. Clujul Med 91: 387-390, 2018.

2. Muñoz JV, Herreros B, Sanchis V, Amoros C, Hernandez V, Pascual I, Mora F, Minguez M, Bagan JV and Benages A: Denta and periodontal lesions in patients with gastro-oesophageal reflux disease. Dig Liv Dis 35: 461-467, 2003.

3. Schroeder PL, Filler SJ, Ramirez B, Lazarchik DA, Vaezi MF and Richter JE: Dental erosion and acid reflux disease. Ann Int Med 122: 809-815, 1995.

4. Meurmann JH, Toskala J, Nuutinien P and Klemetti E: Oral and dental manifestations in gastrooesophageal reflux disease. Oral Surg Oral Med Oral Pathol 78: 583-589, 1994.
5. Gregory-Head B and Curtis DA: Erosion caused by gastrooesophageal reflux: Diagnostic considerations. J Prosthodont 6: 278-285, 1997.

6. Bartlett DW, Evans DF and Smith BG: The relationship between gastro-oesphageal reflux disease and dental erosion. J Oral Rehabil 23: 289-297, 1996.

7. Bartlett DW, Evans DF, Anggiansah A and Smith BG: A study of the association between gastro-oesophageal reflux and palatal dental erosion. Brit Dent J 181: 125-131, 1996.

8. Pontefract HA: Erosive toothwear in the elderly population. Gerodontology 19: 5-16, 2002.

9. O'Sullivan EA, Curzon ME, Roberts GJ, Milla PJ and Stringer MD: Gastroesophageal reflux in children and its relationship to erosion of primary and permanent teeth. Eur J Oral Sci 106: 765-769, 1998.

10. Moazzez R, Bartlett D and Anggiansah A: Dental erosion, gastro-oesophageal reflux disease and saliva: How are they related? J Dent 32: 489-494, 2004

11. Loffeld RJ: Incisor teeth status in patients with reflux oesophagitis. Digestion 57: 388-390, 1996.

12. Jarvinen V, Meurman JH, Hyvarinen H, Rytömaa I and Murtomaa H: Dental erosion and upper gastrointestinal disorders. Oral Surg Oral Med Oral Pathol 65: 298-303, 1988.

13. Aine L, Baer M and Mäki M: Dental erosions caused by gastroesophageal reflux disease in children. ASDC J Dent Child 60: 210-214, 1993

14. Böhmer CJ, Klinkenberg-Knol EC, Niezen-de Boer MC, Meuwissen PR and Meuwissen SG: Dental erosions and gastro-oesophageal reflux disease in institutionalized intellectually disabled individuals. Oral Dis 3: 272-275, 1997.

15. Myklebust S, Espelid I, Svalestad S and Tveit AB: Dental health behavior, gastroesophageal disorders and dietary habits among Norwegian recruits in 1990 and 1999. Acta Odontol Scand 61: 100-104, 2003

16. Linnett V, Seow WK, Connor F and Shepherd R: Oral health of children with gastro-esophageal reflux disease: A controlled study. Aust Dent J 47: 156-162, 2002.

17. Dahshan A, Patel H, Delaney J, Wuerth A, Thomas R and Tolia V: Gastroesophageal reflux disease and dental erosion in children. J Pediatr 140: 474-478, 2002.

18. Bartlett DW, Lussi A, West NX, Bouchard P, Sanz M and Bourgeois D: Prevalence of tooth wear on buccal and lingual surfaces and possible risk factors in young European adults. J Dent 41: 1007-1013, 2013

19. Pace F, Pallotta S, Tonini M, Vakil N and Bianchi Porro G: Systematic review: Gastro-oesophageal reflux disease and dental lesions. Aliment Pharmacol Ther 27: 1179-1186, 2008.

20. Jaspersen D, Kulig M, Labenz J, Leodolter A, Lind T, Meyer-Sabellek W, Vieth M, Willich SN, Lindner D, Stolte M and Malfertheiner P: Prevalence of extra-oesophageal manifestations in gastro-oesophageal reflux disease: An analysis based on the ProGERD Study. Aliment Pharmacol Ther 17: 1515-1520, 2003.

21. Hirano I and Richter JE; Practice Parameters Committee of the American College of Gastroenterology: ACG practice guidelines: Oesophageal reflux testing. Am J Gastroenterol 102: 668-685, 2007.

22. Zerbib F, desVarannes SB, Roman S, Pouderoux P, Artigue F, Chaput U, Mion F, Caillol F, Verin E, Bommelaer G, et al: Normal values and day-to-day variability of 24-h ambulatory oesophageal impedance-pH monitoring in a Belgian-French cohort of healthy subjects. Aliment Pharmacol Ther 22: 1011-1021, 2005.

23. Ganss C, Lussi A and Schlueter N: Dental erosion as oral disease. Insights in etiological factors and pathomechanisms, and current strategies for prevention and therapy. Am J Dent 25: 351-364, 2012.

24. Magalhães AC, Wiegand A, Rios D, Honório HM and Buzalaf MA: Insights into preventive measures for dental erosion. J Appl Oral Sci 17: 75-86, 2009.

25. Bartlett D, Ganss C and Lussi A: Basic erosive wear examination (BEWE): A new scoring system for scientific and clinical needs. Clin Oral Investig 12 (Suppl 1): S65-S68, 2008.

26. Lussi A, Schaffner M, Hotz P and Suter P: Dental erosion in a population of Swiss adults. Community Dent Oral Epidemiol 19: 286-290, 1991.

27. Aanen MC, Numans ME, Weusten BL and Smout AJ: Diagnostic value of the reflux disease questionnaire in general practice. Digestion 74: 162-168, 2006.

28. Wilder-Smith $\mathrm{CH}$, Materna A, Martig L and Lussi A: Gastro-oesophageal reflux is common in oligosymptomatic patients with dental erosion: A pH-impedance and endoscopic study. United European Gastroenterol J 3: 174-181, 2015. 
29. Stål P, Lindberg G, Ost A, Iwarzon M and Seensalu R Gastroesophageal reflux in healthy subjects. Significance of endoscopic findings, histology, age, and sex. Scand J Gastroenterol 34 121-128, 1999

30. Dua KS, Surapaneni SN, Hafeezullah M, Reddy N, Tatro L and Shaker R: Prevalence of abnormal upper GI findings in apparently healthy volunteers enrolled for research studies. Gastrointest Endosc 69: AB350-AB351, 2009.

31. Marrese M, Guarino V and Ambrosio L: Atomic force microscopy: A powerful tool to address scaffold design in tissue engineering. J Funct Biomater 8: 7, 2017.

32. Zheng X, Hu J, Chen Y, Zhu Y and Chen H: AFM study of the effects of collagenase and its inhibitors on dentine collagen fibrils. J Dent 40: 163-171, 2012.

33. Lussi A and Jaeggi T (eds): Dental Erosion: Diagnostic, Risk Assessment, Prevention, Treatment. Quintessence International, pp55-67, 2012.

34. Goldberg M, Kulkarni AB, Young M and Boskey A: Dentin: Structure, composition and mineralization. Front Biosci (Elite Ed) 3: 711-735, 2011.

35. Ren YF, Zhao Q, Malmstrom H, Barnes V and Xu T: Assessing fluoride treatment and resistance of dental enamel to soft drink erosion in vitro: Applications of focus variation 3D scanning microscopy and stylus profilometry. J Dent 37: 167-176, 2009.

36. Ren YF: Dental erosion: Etiology, diagnosis and prevention A peer reviewed publication. Registered Dental Hygienist Magazine, pp32-38, 2011.

37. Lussi A and Hellwig E: Risk assessment and preventive measures. From diagnosis to therapy: In: Dental Erosion. Lussi A (ed). Vol 20. Monogr Oral Sci, Basel, pp190-199, 2006.

38. Picos AM: Eroziunea Dentara in Noala de Reflux Gastroesofagian Dental erosion in gastroesophageal reflux disease. Edit Med Univ 'Iuliu Hațieganu', Cluj-Napoca, pp11-19, 2014 (In Romanian).

39. Lussi A, Portmann P and Burhop B: Erosion on abraded dental hard tissues by acid lozenges: An in situ study. Clin Oral Invest 1: 191-194, 1997.

40. Lussi A, Jäggi T and Schärer S: The influence of different factors on in vitro enamel erosion. Carries Res 27: 387-393, 1993.

41. Lussi A and Jaeggi T: Erosion-diagnosis and risk factors. Clin Oral Investig 12 (Suppl 1): S5-S13, 2008.

42. Picoş A, Răchişan AL and Dădârlat A: Minimally invasive dental treatment using composites and ceramics in GERD diagnoses patients. Mater Plast 55: 252-254, 2018
43. Vakil N, van Zanten S, Kahrilas P, Dent J and Jones R; Global Consensus Group: The Montreal definition and classification of gastroesophageal reflux disease: A global evidence-based consensus. Am J Gastroenterol 101: 1900-1920, 1943, 2006.

44. Picos AM, Poenar S, Opris A, Chira A, Bud M, Berar A, Picos A and Dumitrascu DL: Prevalence of dental erosions in BRGE: A pilot study. Clujul Med 86: 344-346, 2013.

45. Picos AM, Chisnoiu AM, Lasserre JF, Spinei A, Chisnoiu MR and Picos A: Dental erosion-literature update. HVM Bioflux 5: 135-141, 2013.

46. Picos AM, D'Incau E, Bonafos C, Berar A, Chira A and Dumitrascu D: Intrinsic etiology of dental erosion. J Odonto Stom 43: 56-67, 2014

47. Picos A, Lasserre JF, Chisnoiu A, Berar A, D'Incau E, Picos AM, Chira A, des Varannes SB and Dumitrascu DL: Factors associated with dental erosions in gastroesophageal reflux disease: A cross-sectional study in patients with heartburn. Med Pharm Rep 93: 23-29, 2020

48. Tsichlaki A, O'Brien K, Benson PE, Marshman Z, Johal A, Colonio-Salazar FB, Harman NL and Fleming PS: Development of a core outcome set for use in routine orthodontic clinical trials. Am J Orthod Dntofacial Orthop 158: 650-660, 2020.

49. Nairn W (ed): Principles and Practice of Esthetic Dentistry. 1st edition. Elsevier, pp165-191, 2014.

50. Alhajj MN, Ariffin Z, Celebić A, Alkheraif AA, Amran AG and Ismail IA: Perception of orofacial appearance among laypersons with diverse social and demographic status. PLoS One 15: $\mathrm{e} 0239232,2020$

51. Dong JK, Jin TH, Cho HW and Oh SC: The esthetics of the smile: A review of some recent studies. Int J Prosthodont 12: 9-19, 1999.

52. Romano R, Bichacho N and Touati B (eds): The Art of the Smile: Integrating Prosthodontics, Orthodontics, Periodontics, Dental Technology, and Plastic Surgery in Esthetic Dental Treatment. Quintessence Publishing, pp11791, 2005.

53. Picos A, Vulturar R, Picos A, Chis A, Chiorean I, Piciu A Petrachescu N and Dumitrascu DL: Interleukin-1A and interleukin-1B gene polymorphisms in gastroesophageal reflux disease. Exp Ther Med 20: 3394-3398, 2020. 